\title{
El Positivismo como problema: autores, contenidos y difusión de una 'corriente' europea
}

\author{
Positivism as a problem: \\ authors, content and dissemination of a European 'stream'
}

Paul Juan Montoya Vásquez.

Doctorando en Historia en el Programa de Pos-Grado en Historia de la Escuela de Humanidades de la Pontificia Universidad Católica del Rio Grande del Sur prof.paulmontoya@gmail.com

Resumen: El artículo pretende introducir una discusión sobre la diversidad de categorías que componen el cuerpo teórico denominado positivismo, a partir de la variada producción de los autores europeos que la crítica vincula al mismo. La hipótesis central esbozada aquí es que en el propio medio europeo se produjo un encendido debate en torno a los contenidos o categorías teóricas que comprenderían la enunciación 'positivismo' así como los autores que se convendría harían parte de la referida corriente. De forma que resulta cuestionable utilizar la categoría para referir un conjunto de teorías homogéneo o pacífico. Palabras claves: Positivismo, Método experimental, Autores positivistas.

\begin{abstract}
This article intends to introduce a discussion about the diversity of categories that compose the theoretical body called positivism, from the varied production of European authors that critics link to it. The central hypothesis outlined here is that in European sphere itself it's produced an intense debate over the subject or theoretical categories that comprise the enunciation 'positivism' as well as authors claimed to be part of the referred movement. Therefore, resulting in a questionable use of the category to refer to a set of homogeneous or peaceable theories.
\end{abstract}

Keywords: Positivism, Experimental method, Positivist Authors. 
Una aproximación, aun inicial, a la literatura sobre el tema del positivismo y su recepción en los medios latinoamericanos sorprende en razón del abundante número de escritos y la diversidad de sus perspectivas. La primera constatación que se desprende de su estudio es que, sin excepción, en todos los medios de habla luso-hispana existen trabajos dedicados al referido proceso. En algunos casos (México, Brasil, Argentina, Venezuela) el tema se constituyó en el foco central de un número amplio de trabajos al punto de significar un esfuerzo considerable su reunión y análisis. Una segunda constatación se dirige hacia la diversidad de perspectivas o enfoques de estos estudios. Además de los problemas de orden teórico, para los investigadores del tema la definición de lo que comporta el corpus positivista, así como de las formas de recepción que ello hubo adquirido en determinado medio, desprende especiales dificultades o un carácter ambiguo. Esto ha generado en las últimos años una discusión más elaborada, en la que se inscriben posiciones diversas, sobre los contenidos implicados en la categoría "positivismo", así como en los métodos o perspectivas mediante los cuales es analizada su apropiación por un intelectual, estadista o un grupo de estos en cada medio.

En este artículo, pretendo exponer algunas de las diversidades de las que se desprende el carácter ambiguo de la categoría en cuestión, con el objeto de establecer los elementos a partir de los cuales es posible un estudio de las apropiaciones locales de lo que se denomina positivismo.

Existen diversas perspectivas de aproximación a la reunión de categorías que se enuncian con la denominación en cuestión. Entre los especialistas el término es presentado como refiriendo objetos que transitan entre un sistema filosófico (GUTHLIN, 1873; CHARLTON, 1959; SIMON, 1963; DE LA VEGA, 1998; JÚNIOR, 2003; OUELBANI, 2010), un método o forma de epistemología (GRUBER, 1893; NEGRI, 1981; BILBAO, 1986; KOLAKOWSKI, 1988; KREMER-MARIETTI, 1997; SALDARRIAGA, 2006), un desarrollo sociológico (GURVITCH, 1955; FORTE, 1998; BENOIT, 1999), una programa político (ANDERLE, 1988; HALE, 1991) o una combinación diversa de varios de estos elementos (MAGNINO, 1955; WOODWARD, 1971; ZEA, 1976; TERAN, 1983; POGGI, 1987; GUADARRAMA, 2004; ARANA, 2007; TRINDADE, 2007). Todo ello se complejiza aún más a nivel de los estudios que se concentran en las aplicaciones del referido corpus a áreas específicas como las ciencias experimentales, medicina, derecho, psicología criminal, educación, política, historiografía, etc. en los también diversos medios locales. De esa forma, es posible que 
un modo más adecuado de presentar los contenidos de las tesis positivistas incida en la exposición de estas diferentes aproximaciones, a fin de procurar algunos marcos de análisis o convenciones.

\section{Comtismo y método}

Tradicionalmente la presentación del corpus positivista es organizada a través de escuelas o sistemas filosóficos. De ese modo, la delimitación de los autores y doctrinas que el mismo envolvería es establecida por la presencia o desarrollo de las categorías teóricas, a partir de las cuales es reconocido dicho corpus, en los escritos o sistemas de determinado autor y el de sus interlocutores o continuadores. En esta forma de introducción a la temática, las posiciones varían entre el enfatizar la exclusividad del término en torno a los contenidos y reproducción de los escritos de Comte ${ }^{1}$ (consecuentemente, distinguir otras tendencias, escuelas y autores hacia fuera del ámbito de la denominación) y el establecer relaciones variablemente permisibles con supuestos nuevos desarrollos de la filosofía comteana, no necesariamente ortodoxos, en autores como Littré, Claude Bernard (1813 - 1978), Hippolyte Taine (1828 1893), John Stuart Mill (1806 - 1873), Spencer, entre los más relevantes.

En el primer caso, la categoría positivismo es identificada con el comtismo o sistema filosófico difundido por quien enunció el término e hizo amplio uso del mismo para distinguir los contenidos de sus tesis ${ }^{2}$. Desde esta perspectiva, el corpus teórico adquiere marcos definidos y aparentemente claros. Positivismo y positivistas son

\footnotetext{
${ }^{1}$ Augusto Comte vivió entre 1798 - 1857 e inicia la producción de sus escritos hacia la década de 1820, en que comienza a definir las principales líneas de su sistema (Opúsculos de filosofía social: 1819-1828, Porto Alegre: Globo, 1972). En el decenio siguiente, publica en 6 volúmenes el Curso de filosofía positiva (Madrid: Andrómeda, 2004), primera presentación extensa de sus ideas, por el que alcanzará un creciente reconocimiento dentro y fuera de Francia. A fines de la década del 40 publica una síntesis dirigida a explicitar los sentidos de su sistema, Discurso sobre el espíritu positivo (Buenos Aires: Aguilar, 1965), reeditada en 1851 como introducción a su escrito Sistema de política positiva, en que intenta establecer los marcos de la Religión de la Humanidad que fundara cuatro años antes. Con esa misma intención publica en 1852 el Catecismo positivista (París: Garnier, s/f). Una biografía intelectual actualizada de Comte en GOBERNA FALQUE, 2012.

${ }^{2}$ Existe discrepancia en cuanto a la acuñación original del término así como de los contenidos implícitos en el mismo. Algunas posiciones afirman la antecedencia del Conde de Saint Simon (1760 - 1825) de quien Comte fue discípulo (FORTE, 1998). No obstante, se coincide en que fue este último quien popularizó el mismo así como su método.
} 
términos que involucran aquellos escritos, debates y continuadores, en diferentes grados de ortodoxia, de Augusto Comte. De esa forma, el criterio de clasificación de los escritos y autores positivistas suele realizarse de acuerdo al grado de fidelidad o sintonía con que se adoptan las categorías difundidas por el mismo, el modelo más común es el de Ortodoxos-Heterodoxos. No obstante, este campo de definiciones ha sido objeto de disputas, hecho que contribuyó a que diversos especialistas conviniesen en afirmar dos etapas distinguibles e incluso contradictorias en el desarrollo del sistema de Comte. La de sus primeros escritos, que en opinión de algunos sería aquella que realmente contiene los desarrollos del método positivo. Y un segundo momento en que Comte extiende las derivaciones metafísicas de su sistema que, según afirman sus críticos, representarían una desviación o incoherencia de los sentidos originales de su filosofía, encontrando las posibles causas en factores de índole personal ${ }^{3}$. Pasaré ahora a exponer algunos de los contenidos relevantes de los escritos comteanos.

Precedido de una discusión creciente sobre el tema en los países europeos, uno de los puntos en que los contemporáneos de Comte observarán la originalidad o novedad de sus categorías es el énfasis en la crítica a un modelo de conocimiento, privilegiado durante siglos en los medios occidentales, resumido en el enunciado “escolástica". El presupuesto central de este modelo es la existencia de esencias o formas de definición pura, inscritas en los individuos u objetos (naturaleza), para cuya captación última o conocimiento el intelecto humano precisaría de diversos modos de asistencia divina. Esta forma religiosa o trascendente de definir las realidades fue progresivamente cuestionada y redefinida en el debate occidental, dando origen a convenciones provisionales que gradualmente se aproximarían de la negación de todo

\footnotetext{
${ }^{3}$ La primera escisión importante de la escuela filosófica fundada por Comte es la de su discípulo y amigo personal Émile Littré (1801 - 1881), filósofo y lexicógrafo francés, que fue uno de los más activos difusores de sus escritos. Hacia la década del 50, especialmente a partir de la publicación del Sistema, se distancia de las posiciones del mismo. En 1863, publica una exposición de las tesis comteanas en donde define sus posiciones discordantes, Auguste Comte et la philosophie positive (París: Hachette, 1863). Para Littré la única explicación posible de la contradicción representada por las tesis que Comte defendería en su "segunda etapa" (incoherencia) sería una supuesta insanidad o debilitamiento mental de su antiguo maestro. De forma que la auténtica filosofía positivista estaría contenida en el Curso de Comte y sus escritos tempranos, que deberán ser distinguidos del resto de sus textos (GUTHLIN, 1873; CHARLTON, 1959). En Inglaterra, Stuart Mill, que acompañara de cerca los desarrollos iniciales de Comte, emitiría juicios menos críticos sobre las posibles contradicciones de su segunda período, aun cuando en su escrito de 1865, Auguste Comte and positivism, considerase "ridículos" algunos detalles derivados de la religión de la humanidad (STUART MILL, 1972: 166).
} 
tipo de trascendencia ${ }^{4}$. Los escritos comteanos son una de las primeras formas de negación radical de cualquier modalidad de conocimiento trascendente y, entre otras razones, adquirirán repercusión debido al énfasis de la crítica enunciada por su autor así como por la propuesta de aplicación, supuestamente eficaz, del método o modelo de conocimiento científico a la disciplinas sociales, que se distinguirían de toda forma de asistencia divina o trascendencia.

La afirmación en que Comte sustenta su sistema es el reconocimiento de que el ser humano solo tiene aptitud o posibilidad de conocer fenómenos, esto es, hechos específicos evidenciados por la realidad que le es inmediata. La segunda constatación es que este conocimiento es relativo, es decir, la apropiación de los fenómenos o hechos solo podrá ser operada a partir de sus manifestaciones exteriores y no de sus esencias o causas últimas que, en la posibilidad de existir, no son pasibles de ser aprehendidas por el intelecto humano en formas que puedan serle útiles. En cambio, lo que efectivamente puede ser captado son las secuencias de fenómenos y las relaciones que a partir de ello se establecen entre los mismos, antecedentes y consecuentes. Para Comte, la observación de estas relaciones que vinculan fenómenos entre sí evidencia condiciones que se repiten constantemente, de lo que se deriva la posibilidad de discernir y establecer leyes o relaciones necesarias, pasibles de abstracción. En consecuencia, lo que podemos conocer efectivamente (de modo positivo) de los fenómenos son sus manifestaciones exteriores y las formas recurrentes como operan en las realidades temporales, leyes científicas ${ }^{5}$ que en su aplicación a los estudios sociales se traducen a leyes históricas. Serán la determinación de este tipo de constantes del comportamiento humano y de las realidades que lo circundan las que deben guiar los modelos o formas de organización más adecuados para el desarrollo y satisfacción de los individuos.

\footnotetext{
${ }^{4}$ Las convenciones conceptuales difundidas durante lo que se denomina "período ilustrado", siglo XVIII, son uno de los momentos más conocidos de este proceso. Ellas se localizan en un punto intermedio del mismo, por cuanto su afirmación de las aptitudes de la "razón humana" para definir las realidades se sustenta en el hecho de ser ésta un elemento inscrito en los individuos por la divinidad. La razón es, en última instancia, la llave de comprensión de la realidad por ser informada o tener un origen divino (VALVERDE, 2003).

${ }^{5}$ De esa forma: "Fourrier formuló las realidades cuantitativas de los fenómenos térmicos sin preocuparse de la 'naturaleza' del calor; Cuvier elaboró las leyes de la estructura de los organismos sin plantear hipótesis acerca de la 'naturaleza' de la vida; Newton describió los fenómenos del movimiento y de la atracción sin especulaciones metafísicas sobre la esencia del cuerpo y del movimiento" (KOLAKOWSKI, 1988: 75).
} 
Labor para la cual propone la ciencia de la que, por una mayoría, es considerado fundador.

El método a partir del cual Comte postula la aplicación a los estudios sociales de este giro epistemológico, en lo que tiene antecedentes claros entre los teóricos ingleses de los dos siglos precedentes así como los filósofos ilustrados franceses (KOLAKOWSKI, 1988: 24), es el denominado científico o positivo. La dinámica del mismo se deriva de los contenidos de su enunciado. Lo "positivo" refiere aquello que es dado o se evidencia a la observación; cierto, efectivo, cuya apreciación no ofrece duda o es pasible de comprobación, consecuentemente, tiene un carácter práctico o de aplicación mensurable. Del énfasis en ello se deriva el método de las ciencias que se resume en la dinámica de observación-experimentación-comparación (observar fenómenos, analizar su composición o manifestaciones y compararlos entre sí con el objeto de establecer leyes). Una de los rasgos más distintivos de los escritos comteanos es la exposición de un posible desarrollo de la aplicación de este modelo a los estudios sociales. Este será uno de los programas centrales del proyecto comteano.

El comtismo se constituye como una crítica radical al modelo escolásticoiluminista, específicamente en el punto en que este modelo postula el conocimiento de las realidades (hombre, sociedad, ciencias, política, historia, moral, etc.) como esencialmente informadas por un sustrato trascendente o metafísico del cual deberá derivarse la interpretación y proyecto prospectivo de las mismas, y una propuesta de aplicación del método desarrollado por las ciencias, enunciado como positivo, al estudio de las diversas realidades sociales con la consecuente generación de un proyecto social depurado de estos elementos "pre-modernos". Este objetivo será una de las motivaciones que informarán la obra de Comte, no obstante, como sabemos, una cosa es lo que un autor dice o hace explícito sobre su proyecto (declaración de principios) y otra, no siempre equivalente, la consecución o desarrollos concretos del mismo (lo que hará).

El autor francés percibe en su análisis del desarrollo histórico de las realidades sociales (aplicación de su método) dos tendencias holísticas que atraviesan la historia a partir de cuya extensión deduce sus leyes más conocidas. La primera de estas tendencias del devenir humano es enunciada como la dirección de lo simple a lo complejo, por la cual todas las realidades iniciarían su existencia como elementos poco desarrollados afectados por una complejización constante (seres vivos, organismos sociales, 
conocimientos, etc.). La segunda es descrita como el tránsito constante de lo general a lo particular, en el sentido en que las realidades inicialmente dispersas y difusas se orientan hacia la conformación de síntesis en torno de elementos integradores. Para Comte, estás dos dinámicas antinómicas (contradictorias en apariencia) son el trasfondo o clave de interpretación de todo el proceso de evolución del hombre y su espacio circundante, cuya constatación le permitirá enunciar respectivamente dos leyes epistemológicas o de evolución intelectual.

La ley de los tres estados, que se resume en el paso progresivo del desarrollo intelectual humano de lo que Comte llama período "teológico", caracterizado por el énfasis en el conocimiento de las realidades últimas (esencias) aprehendidas mediante el concurso de agentes sobrenaturales, hacia el "metafísico", que mantiene el referido énfasis pero procurando su conocimiento en la naturaleza inscrita de las cosas, para derivar finalmente en el "positivo", que desecha la pregunta por las esencias o naturalezas inmanentes a partir de la negación de la existencia de las mismas, o la posibilidad efectiva de conocerlas, y dirige el énfasis hacia las manifestaciones sensibles de las realidades o cosas. Un desplazamiento de la pregunta del "porque" (causas últimas) por la del "como" (caracteres y formas de relación) se desenvuelven los elementos de la realidad. En un esfuerzo de esquematización, Comte se ocupa de establecer los marcos temporales en que aproximadamente habrían primado cada uno de estos modelos de conocimiento. Él mismo sería parte del momento inaugural del período o estadio positivo.

La ley de clasificación de las ciencias se desprende de la tendencia holística hacia la concentración de las formas de conocimiento. Estas habrían sido informadas progresivamente por el método positivo (elemento integrador), comenzando por las ciencias abstractas. De esa forma, Comte establece una secuencia jerárquica entre matemática, astronomía, física, química, biología, sociología, a las que posteriormente incrementará la moral. Todas ellas deberán hacerse particulares o concurrir en la ciencia de la sociedad, como el punto culminante de aplicación del modelo de conocimiento positivo.

Derivada su primacía de estas dos leyes, la ciencia social o sociología dividiría su ámbito de estudio u objeto también en dos momentos, distinguidos en razón de su aplicación a las funciones sincrónicas y diacrónicas en que se evidencian las realidades comunitarias. El primero será la estática o análisis del organismo social en relación con 
sus condiciones de existencia, es decir, el estudio de la configuración de una determinada agrupación de individuos atendiendo al conjunto de sus relaciones presentes (orden). El segundo denominado dinámica, se dirige a la descripción de las etapas recorridas por las sociedades, específicamente, a la deducción de las leyes por las cuales estas evolucionan hacia formas de existencia cada vez más complejas y específicas (progreso).

El método comteano así, al igual que el resto de sistemas teleológicos modernos, se traducirá en un elaborado esquema de análisis e interpretación de las realidades sociales con pretensiones holísticas, esto es, agotarlas o reducir sus manifestaciones a abstracciones cerradas o que se sustentan en la idoneidad de su método. Reemplazar una teleología mística por otra pretendidamente científica.

Por motivaciones programáticas, Comte decide desarrollar, a partir de sus escritos de finales de la década de 1840, una modelo religioso secular. Ello en razón de la renuncia a la posibilidad de un tránsito rápido o pacífico de los individuos de esquemas de pensamiento teológicos y metafísicos hacia el positivo, así como del deseo de acelerar este proceso. El autor francés considera en ese momento la necesidad de elaborar un sucedáneo o elemento de tránsito que pudiese canalizar las tendencias metafísicas persistentes en el espíritu humano. Opción a partir de la cual irá transitando progresivamente hacia los límites de las formas de conocimiento que intentó desacreditar con entusiasmo en sus primeros escritos. Las consecuencias de este proyecto serán la creación de un culto o Religión de la Humanidad, al que implementará de una jerarquía, ritos y dogmas supuestamente informados por el método positivo.

Esta última etapa de Comte, (detallada en varios estudios: HUBERT, 1943; PRIETO, 1944; THOMPSON, 1995; BENOIT, 1999; JUNIOR, 2003; GOBERNA, 2012), fue cuestionada por sus contemporáneos y motivaría la escisión de sus intérpretes en dos conjuntos heterogéneos. De un lado, aquel que secundaría el proyecto religioso-secular del mismo ${ }^{6} \mathrm{y}$, de otro, quienes afirmarían una reversión del proyecto comteano. Entre estos últimos se encontraron algunos de sus interlocutores más reconocidos, como Littré y J. S. Mill. Las versiones del sistema positivista comteano que ambos se preocuparían en elaborar, en 1863 y 1865 respectivamente, que incidirían en las distinciones entre lo que el autor francés enunció como las dos etapas o

\footnotetext{
${ }^{6}$ Pierre Laffitte (1823-1903), fue uno de los principales animadores de este grupo, sucesor de Comte en la dirección de la Iglesia Positivista, que tuvo también continuadores entre los medios latinoamericanos.
} 
momentos de su filosofía y que presumiblemente obedecieron a los riesgos que los mismos percibían derivarse de las "desviaciones" de las tesis comteanas, son un elemento importante a tener en cuenta. Entre los intelectuales de los medios latinoamericanos, la difusión de las observaciones formuladas por Mill, Littré y otros comentadores sobre el referido sistema, tendrían un efecto ostensible sobre las lecturas o formas de apropiación que se realizarían de las tesis del positivismo ${ }^{7}$.

\section{Método y Episteme}

Un grupo importante de estudios dedicados al tema del positivismo desiste de la perspectiva que limita sus contenidos al proyecto comteano, dirigiendo en cambio el foco hacia el método o modelo de conocimiento a partir del cual este desarrolló sus principales tesis o categorías. La filosofía o sistema positivista se definiría así por una serie de elementos característicos del discurso moderno como fenomenalismo, nominalismo, negación axiológica y acento en el método científico, que reunidos en forma de una crítica al modelo escolástico (los tres primeros) y un giro epistemológico (método) darían forma al modelo positivista. Desde esta perspectiva, centrar la definición del sistema en los contenidos de su método, las tesis del positivismo y los autores que las desarrollan no estarían limitados a la esfera de Comte y los continuadores de su proyecto. Sin debatir la relevancia del filósofo francés, quien en su primera etapa realiza una presentación elaborada del método y populariza la denominación, se distingue el enunciado con que es difundido el modelo de los elementos o categorías que convencionalmente lo definen.

Desagregados sus contenidos, el método o métodos positivistas tendrían así desarrollos anteriores perceptibles desde el inicio del periodo moderno. En algunos casos, como el del filósofo escocés David Hume (1711 - 1776) o el Conde de Saint Simon, elaboraciones de éste que reunirían todos sus elementos reconocidos

\footnotetext{
${ }^{7}$ Pienso que la difusión de las categorías del positivismo comteano entre los medios latinoamericanos fue mediada, de diferentes formas, a partir de las observaciones que los ex-discípulos de Comte difundirían sobre la misma. Ello se percibe, entre otros elementos, especialmente en la referencia que comúnmente los intelectuales locales harían de los escritos de Mill, Littré y otros comentadores al citar las tesis comteanas, especialmente del lexicógrafo francés. Desarrollo con mayor amplitud este tema en un artículo de próxima aparición: 'Método y Doctrina. Lecturas del Positivismo Latinoamericano' (previsión: 2020).
} 
(KOLAKOWSKI, 1988: 46; FORTE, 1998: 51). El mismo sería objeto de formulaciones posteriores por parte de autores, en no pocos casos, distantes de las tesis del sistema comteano o críticos de sus derivaciones "metafísicas".

Al igual que otras corrientes o sistemas filosóficos, el positivismo fue objeto de disputa en cuanto a sus contenidos "auténticos" por parte de los intérpretes de quien convencionalmente se afirmaría ser su primer difusor. La distinción más evidente de ello sería la división entre heterodoxos o aquellos que, como Littré, acentuaron los desarrollos del método distinguido por Comte, contenidos principalmente en el Curso, y ortodoxos, quienes realizarían un esfuerzo teórico por establecer líneas de continuidad entre los dos momentos comteanos (salvar la coherencia) ${ }^{8}$.

Además de Littré, los especialistas reconocen entre los interlocutores no ortodoxos del método positivista, cuyos escritos obtendrían especial difusión entre la intelectualidad de algunos medios latinoamericanos, al médico francés Claude Bernard ${ }^{9}$. Crítico severo de las derivaciones metafísicas del sistema de Comte, Bernard dedica sus esfuerzos a la aplicación del modelo o método científico en la investigación médica (PETIT, 1978). Su difundido texto de 1865, será producto de su práctica investigativa a partir de la cual formula un nuevo desarrollo del método experimental (positivo). El fisiólogo incide en la necesidad de introducir al estudio de las ciencias médicas el principio de la experimentación (distinguir la dinámica del como los fenómenos ocurren, de cualquier especulación metafísica sobre el porque). Partiendo del presupuesto, enfatizado por Comte, de que no nos es posible conocer la esencia o causas últimas de las cosas (fenomenalismo), el estudio de la fisiología humana deberá ser realizado a partir del análisis de sus manifestaciones inmediatas, de modo que puedan establecerse secuencias regulares entre manifestaciones y reacciones (frecuencias), esto es, abstraer leyes biológicas. En ello encuentra el objetivo último de la ciencia médica y de toda filosofía natural: conocer la ley de los fenómenos (CAPONI, 2001).

\footnotetext{
${ }^{8}$ Durante las dos décadas posteriores al fallecimiento de Comte, en 1857, el grupo de estudiosos simpatizantes del método positivo, representado por Littré y Bernard, a quienes autores como Charlton agrupan en la denominación Les vrais amis du positivisme (los verdaderos amigos del positivismo), establecerían un debate continuo con los comteanos ortodoxos, representados por la Iglesia Positivista. Esta tendencia se combinó con la labor de propaganda en otros medios de observaciones derivadas de las "desviaciones" del comtismo (GUTHLIN, 1873; FOUILLÉE, 1896; CHARLTON, 1959). Como se dijo, esta discusión "local" producirá efectos en las formas como la corriente será difundida en otros medios.

${ }^{9}$ Indicado como el iniciador de la fisiología contemporánea, sintetiza las conclusiones de la aplicación del método positivo a sus estudios fisiológicos en su trabajo de 1865, Introducción al estudio de la medicina experimental (Barcelona: Fontanella, 1976).
} 
La obtención de leyes de la fisiología humana se deriva así de la aplicación del método al estudio de las formas de relación entre las causas inmediatas o condiciones de existencia y las manifestaciones orgánicas del mismo (antecedentes y consecuentes), como lo son una enfermedad o una reacción favorable, por ejemplo. Basado en sus pesquisas deductivas, Bernard elabora un desarrollo de lo que llama método experimental que resumirá en los pasos Observación-Hipótesis-ExperienciaInterpretación. Una forma depurada de aplicación de la epistemología científica a la formulación de leyes, canalizadas esta vez hacia las ciencias de la vida. El médico francés introduce así nuevas aristas al corpus teórico positivista que adquieren especial relevancia en razón de la difusión que tendrían sus escritos en el medio científicoacadémico, durante las últimas décadas del siglo $\mathrm{XIX}^{10}$.

En los medios latinoamericanos los textos de Bernard obtendrán especial recepción al interior de las facultades de medicina, ámbito por el cual las tesis derivadas del método positivo se introducirían de forma sutil en los medios en que éstas eran especialmente cuestionadas por los sectores intelectuales, por ejemplo, los espacios académicos colombianos (SALDARRIAGA, 2006). De esa forma, el análisis de las apropiaciones y desarrollos de los que serían objeto las tesis positivistas, entre los investigadores vinculados a las ciencias médicas locales, deberá prestar especial atención al filtro que escritos como los de Bernard constituyeron en este proceso. Las traducciones de las tesis positivistas al debate médico local, operadas por especialistas o intelectuales, no sería realizada, en una mayoría de los casos, a partir de lecturas directas de Comte y sí de las versiones que del método positivo difundirían "heterodoxos" como Bernard.

Un desarrollo también relevante del método positivo es el elaborado por el filósofo e historiador francés Hippolyte Taine ${ }^{11}$, quien intentará extender el mismo al dominio de la historiografía. Defensor de un modelo cientificista en los estudios históricos, Taine repite en su campo de investigación la operación de Bernard, aplicar el

\footnotetext{
${ }^{10}$ Además de su Introducción, sus escritos de 1865 'Du progrés dans les sciences physiologiques' (Revue de deux mondes, 58, p. 640-663) y de 1878 Leçons sur les phénomênes de la vie communs aux animaux et aux végétaux (Paris: PUF, 1947). No conozco traducciones de estos últimos. Algunas biografías de BERNARD: OLMSTAD, 1951; VIRTANEN, 1960; MARTí, 2006.

${ }^{11}$ Reconocido por sus estudios sobre el antiguo régimen y la revolución francesa, Taine dedicará atención especial a la reflexión teórica sobre la disciplina (CHEVRILLON, 1932). El más importante de sus trabajos en este punto será "La Introducción al estudio de la Historia experimental", publicada como introducción a su libro Historia de la literatura inglesa en 1864 (Buenos Aires: Alfaguara, 1977).
} 
método de las ciencias al análisis de los fenómenos o hechos de la historia, con el objeto de abstraer secuencias y leyes equivalentes. El presupuesto de ello es la renuncia a conocer las esencias o sentidos providencialistas que informan los estudios del devenir histórico, en favor del análisis de los hechos específicos a los que tenemos acceso por medio de las fuentes documentales, objetos pasibles de la aplicación del método experimental.

Los registros de sucesos por medio de los cuales accedemos al conocimiento del pasado, al igual que el cuerpo humano en el caso de la fisiología, posibilitan su experimentación o sometimiento a operaciones científicas. El historiador francés establece su método crítico en cuatro etapas o procedimientos. La distinción de los hechos históricos presentes en un documento, su subdivisión en grupos o categorías, la definición del sentido de las mismas en términos breves (enunciados), y su descripción a través de secuencias y relaciones lógicas, esto es, una narración de los hechos que adquiere sentido o coherencia no en sus presupuestos metafísicos (filosofías de la historia) y sí en la captación de las leyes o procesos en los que el análisis muestra estar estos inseridos (la parte en el todo). De esa forma Taine define su proyecto, introducir el estudio de las realidades históricas al ámbito de las ciencias, en consecuencia, postular una ciencia histórica ${ }^{12}$.

Entre los disidentes ingleses de Comte, es usual reconocer especialmente a John Stuart Mill ${ }^{13}$. Como se dijo, Mill publicó un ensayo crítico sobre las tesis del mismo pocos años después de su muerte. Posteriormente, en sus Memorias relata su aproximación juvenil a las propuestas epistemológicas del también joven Comte, con quien entablaría una amistad intelectual epistolar, fluida durante algunos años. Su distanciamiento definitivo se produce a inicios de la década de 1850, en razón de sus

\footnotetext{
${ }^{12}$ Taine es usualmente incluido como uno de los "miembros maduros" del grupo de historiadores que introducirían la historia positivista al medio francés, vinculados a partir de la Revue Historique fundada en 1876. El carácter "positivo" de este proyecto historiográfico ha sido cuestionado en razón de tratarse únicamente de un esfuerzo de crítica de fuentes que no incorporaría la tendencia hacia la obtención de leyes (históricas), a semejanza de las ciencias exactas (CARDOSO, 2001; REIS, 2004). Como se observó, no es ese el caso de Taine, quien postula la aplicación del método de las ciencias en todas sus consecuencias. En ello debe verse la necesidad de distinguir entre los diferentes desarrollos reunidos en la denominación 'historiografía positivista' (DEVOTO, 1992).

${ }^{13}$ Además de su escrito de 1865 sobre las tesis del autor francés, los trabajos filosóficos más difundidos de Mill son Sistema de Lógica, de 1843 (São Paulo: Abril cultural, 1984), Sobre la libertad, de 1859 (Madrid: Alianza, 2002) y El utilitarismo, de 1863 (Madrid: Alianza, 2004). También sus Memorias, de 1873 (Madrid: España moderna, s/f.).
} 
críticas al Sistema, publicado el 51. Mill se ocupa de introducir la crítica al modelo tradicional de conocimiento especialmente en los ámbitos de la lógica y la psicología, vinculando ambos saberes. Su afirmación central es que las doctrinas metafísicas y sociales desentendidas de la realidad, por tanto falsas, encuentran su fundamento en la creencia de que la mente humana es capaz de entender la verdad independientemente de la observación y de la experiencia, esto es, a partir del dato revelado (dogma) o de la especulación metafísica (razón iluminista). De esa forma, en su texto de 1843, desarrolla una formulación y descripción detallada de las reglas del comportamiento inductivo (formas de conocimiento de la realidad mediante la experiencia) en las ciencias empíricas o sociales.

El giro que Mill introduce en la lógica ${ }^{14}$ se sintetiza en el otorgar a la noción de "causa" un sentido no metafísico. El autor inglés veía en ésta a un simple fenómeno que, en la observación, se manifiesta como condición suficiente de otro fenómeno. Basado en ese presupuesto, el esfuerzo por obtener un conocimiento suficiente o pleno de las cosas deberá estar informado por reglas (método) que tienden a establecer la sucesión constante de acontecimientos, en la procura por continuidades y diferencias, y la consecuente percepción de relaciones causales entre un hecho y otros, es decir, leyes de la lógica. Mill introduce así un desarrollo del método positivo o científico al ámbito de la abstracción, ensayando en sus escritos posteriores aplicaciones diversas de esta supuesta "llave del conocimiento" a las ciencias económicas, la psicología, la moral y la producción de categorías introducidas por los utilitaristas ingleses (COBO, 1994).

Herbert Spencer ${ }^{15}$, quien se inicia en los estudios filosóficos acompañado de las simpatías intelectuales de John S. Mill, sería entre los autores que los especialistas señalan dentro de los desarrollos positivistas, en varios aspectos, el más distante de la

\footnotetext{
${ }^{14}$ Razón por la que su texto será utilizado como manual de curso en las principales universidades de medios como el Uruguay (ARDAO, 1950), Perú (SALAZAR, 1967), Colombia (JARAMILLO, 1964), entre otros, durante la segunda mitad del siglo XIX.

${ }^{15}$ Ingeniero de formación, Spencer (1820 - 1903) inicia la publicación de sus escritos, en 1850, con Social Statics (Estática Social, Sudáfrica: Editorial Innisfree - versión Kindle 2014). Antecedente del conjunto de textos que compondrían su Sistema de filosofía sintética, a través de los cuales introduce al debate sus principales tesis. Dentro del mismo los escritos más difundidos serán Primeros principios 1862 (Madrid: Fernando Fé, 1887), Principios de Sociología 1877-1896 (Buenos Aires: Revista de Occidente, 1947) y Principios de Moral 1898 (Madrid: Lib. Victoriano, 1881). Fuera de su sistema, los escritos más conocidos serán El Progreso, su ley y causa, 1857 (Madrid: La España moderna, s/f); Educación intelectual, moral y física, 1860 (Buenos Aires: Editorial Albatros, 1946), El individuo contra el estado, 1884 (Madrid: Ediciones Orbis, 1984).
} 
figura y proyecto de Comte. Spencer se constituirá también en uno de los filósofos ingleses y europeos con mayor proyección hacia las últimas décadas del siglo $\mathrm{XIX}^{16}$, aun cuando sus escritos serían progresivamente desacreditados al avanzar el siguiente siglo. En los medios latinoamericanos, sus tesis fueron frecuentemente referidas por los denominados intelectuales positivistas, superando en algunos casos las referencias al articulador francés del término. Como se verá posteriormente, ello motivaría que la historiografía regional distinguiese una mayoría de medios en donde el "positivismo adoptado" sería de vertiente spencereana.

Entre los intérpretes europeos de Spencer surgiría, hacia las dos últimas décadas del siglo XIX, un debate sobre las relaciones posibles entre los sistemas filosóficos de éste y Comte. Las posiciones en el mismo variarían desde la percepción de un desarrollo inscrito dentro de los parámetros del comtismo, una suerte de continuismo ${ }^{17}$, a posturas que encontrarían una radical oposición entre las tesis y proyecto social prospectivo difundidos por ambos (SIMON, 1963). En tanto, para algunos de sus intérpretes, Spencer sería uno de los más destacados "discípulos" de Comte y por tanto, junto con éste, el autor más importante del positivismo europeo, para otros sectores, las distinciones entre los contenidos de sus tesis serían evidentes y en consecuencia estaríamos frente a dos sistemas sustancialmente diversos entre sí. Esta aparente indefinición en el debate europeo sobre los límites de la filosofía y proyecto positivista tendría efectos en las apropiaciones y posteriores lecturas que del mismo se realizarán en medios como los latinoamericanos e inscribirían, consecuentemente, ese mismo carácter ambiguo en las particularidades que los discursos sobre el positivismo adquirirán localmente (DE LA VEGA, 1998). Pasaré a exponer los elementos que informan la referida indefinición.

La primera publicación en formato de libro de Spencer se intituló Estática Social (Social Statics), aparecido en 1850. El término fue extraído por el mismo de un texto de Mill, Principios de economía política (1848), quien a su vez lo utilizaría en referencia a la estática, estudio de la configuración sincrónica de las sociedades (orden), de Comte. En su texto novel, sin embargo, Spencer no se propondría aplicar la teoría sociológica

\footnotetext{
${ }^{16}$ Sus escritos más importantes obtendrán traducciones en más de 15 idiomas, incluyendo por ejemplo el japonés, húngaro, chino, sánscrito (GAUPP, 1930: 55), árabe, nohawk (RUMNEY, 1944: 280).

17 Lecturas de los Primeros principios de Spencer en ese sentido, tendrían uno de sus primeros defensores en el jurista e historiador inglés Fréderic Harrison (1831 - 1923), junto con Mill, uno de los más reconocidos positivistas "heterodoxos" de ese país (KREMER-MARIETTI, 1997).
} 
del francés (a quien en ese momento conocía solo indirectamente por las referencias de Mill y otros autores) y sí esbozar los marcos iniciales de su teoría evolucionista.

En razón de las confusiones generadas por el título de su primer trabajo, Spencer realiza la lectura del Curso de Comte, producto de la cual elabora una crítica a la jerarquización de las ciencias propuesta en el mismo, en un artículo que llamó "Génesis de la Ciencia", aparecido en la British Quarterly Review, el año 1854. No obstante, Spencer continuará utilizando la fraseología identificada con el positivismo comteano, en sus escritos posteriores. En 1857, por ejemplo, publicó su ensayo Ley y causa del Progreso, en el que postulará la validez universal de la ley de la evolución, sin realizar alguna referencia explícita de Comte.

La difusión del trabajo considerado como el eje central de su obra, Primeros principios, y el reconocimiento que adquiere a partir del mismo desde 1862, motivaría las disputas iniciales sobre las supuestas "filiaciones" de su pensamiento, antes referidas ${ }^{18}$. Ello, entre otras razones, produciría en Spencer el deseo de distinguir su producción textual de las tesis del fundador de la Iglesia Positivista.

El año 64, difunde dos ensayos que publica en forma de libro ${ }^{19}$. El primero, que denominó "Clasificación de las ciencias", complementaría su artículo de 1854 cuestionando esta vez el criterio clasificatorio de Comte, basado en las tendencias holísticas de generalidad decreciente y creciente complejidad. En el segundo ensayo, "Razones para disentir de la filosofía de Mr. Comte", haría explícita su distancia del sistema comteano ocupándose de detallar las diferencias entre ambos, exagerando por momentos en sus esfuerzos por desacreditar las tesis de su supuesto antecesor (RUMNEY, 1944: 42). El argumento central de Spencer es que los puntos en común de ambas aproximaciones, relacionados a la crítica epistemológica y a la aplicación del modelo de las ciencias a los estudios sociales (método positivo), no tendrían un origen definido en Comte sino en antecesores a partir de los cuales habrían informado simultáneamente sus escritos. Por otro lado, los desarrollos realizados por ambos desde

\footnotetext{
${ }^{18}$ En 1864, aparece en la Revue des deux mondes francesa, un comentario a su texto de 62, de Augusto Laugel, quien afirma percibir el influjo, no confeso, de Comte en el mismo. Spencer refiere esta reseña como parte de los motivos que lo llevarían a pronunciarse posteriormente sobre el punto (DE LA VEGA, 1998: 156).

${ }^{19}$ The classification of the sciences; to wich are added reasons for dissenting from the philosophy of Mr. Comte, London: Williams and Norgate, 1864 (Classificação das ciências, São Paulo: Cultura Moderna, 1950).
} 
dichos presupuestos se distinguirían en todos los casos y, en algunos puntos, llegarían a ser contradictorios. Spencer explicita su desconocimiento directo de la obra de Comte en el momento de la publicación de su Estática, y procede a detallar sus cuestionamientos a la ley de los tres estados, la referida clasificación de las ciencias, el énfasis comteano en la centralidad de las ideas en el desarrollo humano y, lógicamente, las aristas metafísicas del comtismo (religión de la humanidad). En todos los casos se preocupa de ofrecer alternativas a las tesis de Comte, a quien también critica por desestimar las aplicaciones posibles de la biología evolutiva, que el mismo se encargará de desarrollar.

Este escrito de Spencer, y las referencias que posteriormente haría del tema, permiten establecer con claridad un aspecto, la falsedad de las afirmaciones que lo clasifican como discípulo o continuador de Comte (GAUPP, 1930: 102). No obstante, Spencer suscribe en su totalidad el énfasis radical, característico de la filosofía comteana, en la aplicación del método de las ciencias a la especulación filosófica y sus desdoblamientos en los estudios sociales, esto es, ser informada por la observación de los hechos y dirigirse a la fijación de simultaneidades y sucesiones constantes, bajo el nombre de leyes. Ello no con la finalidad de intentar descifrar una supuesta naturaleza íntima (esencias o primeros principios) de las cosas y de la realidad que las agrupa, sino la de obtener conocimientos precisos y seguros, positivos, de la misma. En este “proyecto común”, Spencer llevará los desarrollos del método positivo, en opinión de algunos de sus intérpretes, a consecuencias más radicales o coherentes que las del propio articulador del enunciado y la definición (RUMNEY, 1944: 42; GURVITCH, 1955: 136). Pasaré ahora a exponer algunos de los puntos relevantes de entre las tesis spencereanas.

En el marco del debate desarrollado hacia las décadas de 1830-60, el autor inglés introduce un nuevo elemento a la crítica del modelo de conocimiento tradicional o “escolástico". Continuando la discusión, Spencer enfatiza en su escrito de 1862 la imposibilidad de una metafísica del conocimiento, reafirmando una noción difundida entre sus contemporáneos, la constatación de las limitaciones del mismo. Su aporte se centrará en revertir la negatividad de dicha crítica hacia un elemento positivo que enunciará como lo Incognoscible. Esta categoría es definida por Spencer como una fuerza oculta al intelecto humano que sería el origen de las realidades y cuyo efecto duradero se traduce (por tanto es perceptible) en el movimiento complejo y constante de 
las cosas, de lo que se desprende la dinámica de evolución. Este elemento oculto en las realidades (primeros principios), caracterizado como un dato positivo por Spencer, es por definición un punto intrínsecamente ciego de nuestro entendimiento, aun cuando auxiliado por la aplicación del método de la ciencias, y todo intento de articulación del mismo derivará en dogmas falsos (mitos) y su correspondiente traducción a proyectos sociales “místicos".

Caracterizado de esta forma, lo incognoscible deberá ser mantenido en el espacio del discurso y prácticas religiosas, y distinguido del ámbito de las ciencias de las que la filosofía y los estudios sociales también harían parte. De ese modo, Spencer postula una fórmula que admite la posibilidad teórica de conciliación entre religión y ciencia, aun cuando en espacios paralelos claramente diferenciados, complementando el énfasis positivista de las limitaciones explicativas del dogma (religión), con la atención a las limitaciones de la ciencia. De la misma forma que el primero es ineficaz para interpretar y definir realidades, la ciencia lo será también para obtener conocimientos ciertos de la fuerza oculta o primeros principios de las cosas, lo incognoscible ${ }^{20}$. Una legitimación discursiva de la potencial convivencia entre fe y razón, traducida socialmente a la relación Iglesia-Estado, que las versiones radicales del discurso liberal decimonónico habrían negado definitivamente.

El autor inglés sustenta de esa forma la tesis central de su proyecto filosófico. Producto del desarrollo de la referida fuerza oculta, que persiste en lo que conocemos como tiempo, las cosas (todo lo existente) se mueven en un ritmo constante y complejo, esto es, evolucionan. Esta dinámica de evolución se evidencia para Spencer como el elemento común a la historia de todos los fenómenos concretos (incluidas las realidades humanas) y por tanto ofrecería la clave maestra de interpretación de los mismos. Entender así la naturaleza del hombre, la de sus diferentes manifestaciones culturales y la de todo lo que le rodea (biología, conocimiento, moral, organización social, etc.) a partir, no de supuestas esencias reveladas o deducidas, sino del análisis de su recorrido evolutivo (el cómo han llegado a ser lo que son).

\footnotetext{
20 Este presupuesto inicial de la teoría spencereana sería utilizado, por algunos intelectuales latinoamericanos del período, para suscribir las tesis positivistas justificando prácticas religiosas personales (QUINTANILLA, 2006). Lo que, desde una lectura segmentada de sus apropiaciones locales, es interpretado por algunos estudios como un contrasentido o supuesta "desviación" de la doctrina (teoría del empate). Como puede verse, el "positivismo religioso", pretendido como una particularidad local, tendría claros referentes europeos.
} 
En consecuencia, del estudio de la evolución de las diversas realidades humanas, deberán obtenerse las secuencias constantes que, definidas como leyes, se constituirán en los principios rectores de un proyecto de articulación social y de organización de todos los saberes humanos. Principios estos que Spencer entiende como los más adecuados a la naturaleza humana, en tanto que descrita (no inscrita) por el desarrollo de su evolución. Como se induce, la garantía en la definición de los mismos se derivará de la aplicación del método científico, comúnmente referido por los teóricos decimonónicos como positivo, al análisis de la historia humana, labor típica de la ciencia sociológica.

A un primer desarrollo de esa labor, la inducción de los "principios" de todos los saberes y realidades humanas descritos por las líneas de su devenir evolutivo, Spencer dedicará el resto de su producción.

\section{Sociedad y políticas positivas}

Comte y Spencer son considerados por una mayoría de los teóricos sociales contemporáneos, junto con Karl Marx (1818 - 1883), los autores decimonónicos de los desarrollos más importantes de la ciencia social. Ello hace natural que, para los estudios que se aproximan al tema de las tesis del positivismo haciendo énfasis en sus derivaciones sociológicas, el análisis signifique una mirada retrospectiva sobre los propios orígenes o fundamentos. Tal vez no sea necesario recordar que Comte es el articulador del término sociología, con el que pretendía enunciar la síntesis o reunión de todos los conocimientos humanos alrededor del método positivo (elemento integrador), aunque en su madurez cediera el lugar de la misma a la moral. Y que a su vez Spencer se apropiara de la denominación para viabilizar un proyecto análogo, centrando su lectura en la dinámica o carácter universal de la evolución (BILBAO, 1986). Por todo ello, las lecturas que desde la sociología se realizan de las tesis positivistas centran especialmente la atención en los desarrollos de ambos autores. El elemento a partir del cual estos son vinculados es, lógicamente, la práctica sociológica o el modo como ella era postulada por sus teóricos decimonónicos.

De la forma en que fue propuesta o introducida, la ciencia social sería la herramienta o campo de conocimiento dirigido al estudio de los momentos de evolución 
de las realidades humanas (historia) y sus diferentes modelos de organización (configuración diacrónica), que se distinguiría de los saberes tradicionales por su aplicación de análisis informados con el método científico, experimental o positivo, cuya composición fue descrita antes (observación de hechos-distinción de secuenciasinducción de leyes). Sin embargo, la investigación de ambos teóricos derivaría, en no pocos casos, en disímiles interpretaciones de las realidades sociales, presumiblemente por las mediaciones también diversas que rodearon su producción. Pasaré a describir algunos de sus postulados sociológicos que adquirieron mayor proyección.

Comte percibe el eje del desarrollo humano en el ámbito intelectual, del que las realidades son meras derivaciones. Su estratificación de tres estados evolutivos se desprende de la observación del desenvolvimiento mental de los hombres, a quienes abstrae en el concepto de humanidad. De esa forma, la difusión del estadio positivo en las sociedades equivaldrá al arribo, de los integrantes de las mismas, a un estado de conocimiento despojado de los apriorismos escolásticos e informado del modelo científico. En la medida en que los individuos sean introducidos (coincidan) a este modo de entender $\mathrm{y}$, por ende, relacionarse con las realidades que le rodean, las sociedades alcanzarán progresivamente un mayor nivel de armonía social y, derivado de la misma, un desarrollo moral y material constante. Dicho de otra forma, en la proporción en que todos los individuos tengan lecturas análogas de la realidad (consenso social), derivadas de la aplicación de un mismo tipo de criterios (conocimiento positivo), se generará una armonía o sinergización tal (orden) que indefectiblemente se verá traducida en un constante, por tanto, auténtico progreso.

Los intérpretes de Comte inciden comúnmente en el desorden político-social francés del período posrevolucionario, así como las protestas generalizadas de 1848 , cuyos excesos el mismo critica con énfasis, como una de las motivaciones evidentes de su deseo por encontrar justificaciones teóricas a un modelo social armonioso, debidamente jerarquizado y respetuoso del principio de autoridad (FORTE, 1998; BENOIT, 1999). Interpretado de esa forma, el "génesis" de la teoría sociológica comteana habría recibido el mismo tipo de motivaciones que las que propiciaron la atención dada a sus tesis en algunos medios latinoamericanos.

Desvanecido el "orden de cosas", en un breve período de tiempo, y frustrados los primeros intentos liberales por legitimar, en la difusión de los derechos iusnaturales, un nuevo modelo social (consenso), al confrontarse con una realidad de caos; retorna al 
debate local la búsqueda de teorías que legitimen una concentración de autoridad y la consecuente jerarquización social que asegure un mínimo de estabilidad, un consenso articulado en torno a la idea de orden ${ }^{21}$. Serían así razones análogas las que mediaron la generación y difusión de las categorías comteanas en los medios europeos y su apropiación por grupos intelectuales latinoamericanos, diversa en cada medio. Atendiendo a la importancia dada por sus contemporáneos a la dimensión simbólica de la realidad (la capacidad de representarse y legitimar el orden de las cosas), es posible que el autor francés acertase al otorgarle un lugar director a las ideas. Aun cuando desde otro ángulo, su importancia radique en el esfuerzo de los individuos por procurar articulaciones teóricas que, reelaboradas de forma convincente (tenidas por verdaderas), contribuyan a la obtención de niveles positivos de consenso, esto es, utilizar estas.

En su Curso, Comte se representa la sociedad estática (en sí misma) como un organismo biológico, de ello se desprende la constatación de principios que, como en el caso de un organismo, dirigen las dinámicas que caracterizan las sociedades. Estos son el consenso social, que define la armonía entre las partes de las mismas, producto de la lógica interna que necesariamente informa su interrelación, la espontaneidad de la sociabilidad y del orden social, que se desprende del modo natural como las sociedades se conforman, y la célula social familiar, que define el elemento mínimo a partir del cual se operan modificaciones sociales. Como se vio, el consenso será una de las categorías base del modelo comteano dirigido hacia el establecimiento del orden, no por la fuerza sino por la persuasión derivada de la autoridad del método (ciencia). La espontaneidad social cuestiona la idea liberal del contrato como fuente generadora de la organización y, por tanto, de la naturaleza de la sociedad ${ }^{22}$. La familia es para Comte el núcleo central de la misma, cuyo modelo de armonía en torno a un "consenso jerárquico" es la mejor prueba de ser esta la vocación de toda sociedad.

\footnotetext{
${ }^{21}$ Un análisis de esta búsqueda de teorías legitimadoras en el México de la segunda mitad del siglo XIX en GUERRA, 1995; PALTI, 2005.

22 La teoría del contrato social, difundida entre los liberales decimonónicos, implicaba la idea de conformación de la sociedad por medio de la ley o contrato fundamental, de donde se deriva el nombre de Constitución. Esta noción fue la base de la práctica liberal que asumía que la emisión de leyes era equivalente a la consecución de orden y desarrollo social. Lo que llevaría, en no pocos casos, a identificar el volumen de creación legislativa con el progreso local, confundir textos legales con la realidad (ALJOVÍN, 2000; NEVES, 2003). Comte, contradice esta noción retomando la idea de sociedad como estado natural del individuo (zoon politicon aristotélico) por la que la sociedad, lejos de ser un producto mental, es anterior al mismo.
} 
De esa forma, la estática comteana se dirige a demostrar que "la validez de un sistema político no puede consistir, esencialmente, más que en su exacta correspondencia con un estado social dado, 'con el orden espontáneo de la sociedad' " (GURVITCH, 1955: 37). La legitimación de un "nuevo orden de cosas" no podrá así establecer su consenso en idealismos religiosos o en supuestos derechos naturales, y sí en las derivaciones establecidas a partir del estudio de las relaciones entre familia, orden natural y estado social. La determinación de este "orden natural", para Comte, deberá estar a cargo del grupo de individuos introducidos en el modelo positivo de conocimiento, aquellos que tienen dominio del supuesto elemento que garantiza objetividad y que, por tanto, serán los más aptos para guiar al resto de individuos a la fase positiva de la historia humana. Como se dijo antes, este programa derivará en el desarrollo del proyecto comteano en la creación de una iglesia secular y la proclamación del autor francés como el gran maestro o cultor de su propia abstracción, la Humanidad.

El modelo político comteano, desarrollado en el Curso, se dirige así a cuestionar los “dogmas" de la soberanía popular y la igualdad de derechos difundidos a partir del discurso revolucionario liberal que, en su concepción, habría destruido las bases de todo posible orden social y desencadenado una anarquía intelectual y moral. Comte se coloca de esa forma como contestatario de los ensayos del radicalismo liberal de entre siglos, una cierta nostalgia de la estabilidad y "armonía" perdidas, pero, a diferencia de los esfuerzos reaccionarios de autores como Burke, De Maistre o Bonald ${ }^{23}$, no postulará un retorno a los esquemas ideológicos pasados y sí un nuevo modelo epistémico fundado en el método científico que, según cree, permitirá restablecer eficazmente el consenso perdido y el consecuente desarrollo armónico. Entendido este último como la aceptación consciente de todos los individuos de "su lugar" en la distribución de funciones y bienes sociales, la supeditación voluntaria del individuo a la sociedad.

Será esta forma original de reacción de la teoría comteana ante los excesos derivados del, como que se convendrá en llamar posteriormente, jacobinismo o liberalismo decimonónico, en función de sustentar su legitimidad en la novedad del método positivo así como sus posibles aplicaciones al medio (uso), las que motivarán la

\footnotetext{
${ }^{23}$ Forte analiza el influjo que Comte habría recibido de la lectura de los escritos de los referidos autores reaccionarios (FORTE, 1998: 38-44). Por su parte, Comte explícita en varios momentos de su obra su admiración por el sistema jerárquico de la Iglesia Católica, que tratará de reproducir en la Iglesia Positivista.
} 
lectura atenta $y$, en algunos casos, entusiasta que un nutrido conjunto de intelectuales latinoamericanos realizarán de los escritos del teórico francés ${ }^{24}$.

El modelo organizativo que determina la preponderancia del conjunto sobre los individuos, se traduce así en una forma de gobierno centralizada que se sustenta en los mismos supuestos. Comte la enuncia como dictadura política positiva, que se transformará en su Sistema en dictadura republicana. La teoría estatal del comtismo se sustenta en la supeditación del individuo al Estado, de forma que aquel queda vinculado al interés común a partir de la renuncia a supuestos derechos por la asunción de los deberes inherentes a la forma de vida social. En el estado positivo la idea de derechos individuales desaparece para ser sustituida por la de deberes sociales que, observados por el conjunto, garantizarán la realización de todos los individuos.

Consecuentemente, por dictadura republicana Comte entiende el gobierno de un presidente o dictador que deberá reservar para sí las funciones legislativas y de ejecución, restando a un reducido Congreso la labor de fiscalización presupuestal. El autor francés se ocupa de describir en el Sistema los mínimos detalles de aplicación de su propuesta, que de modelo de gobierno se convierte así en una receta estatal (LACERDA, 2000), aun cuando en la práctica no sería apropiado en ningún caso con ese nivel de ortodoxia ${ }^{25}$. Así, el aspecto relevante del modelo dictatorial comteano será el esfuerzo por justificar teóricamente, por tanto legitimar en el discurso, la concentración de poderes del ejecutivo, a partir de una teoría sobre la naturaleza de la relación individuo-estado que se sustenta en la aplicación del método de las ciencias (política positiva). Carácter novedoso que atraerá las lecturas de un número creciente de estadistas e intelectuales en diversos medios, entre estos, los latinoamericanos.

\footnotetext{
${ }^{24}$ Basado en una primera aproximación a la literatura política de la época (textos, prensa, discursos parlamentarios), mi hipótesis es que en medios como el Perú, en los que supuestamente el comtismo no habría obtenido el efecto observado en Brasil o México, la introducción de las tesis del mismo al debate político, en el que los intelectuales en estudio tendrían participación activa, se dio a través de referencias indirectas que, aun cuando no explícitas, demuestran el dominio de la fraseología y contenidos comteanos. En el caso de conseguir sustentar la misma, resta saber si ello se debería a las versiones que circularían desacreditando al director de la religión de la humanidad. En ese supuesto, las difusión entre los mismos de textos como los de Mill (1865) y Littré (1863), específicamente las referencias que de ellos se harían, son una pista singular. Planteo una análisis amplio de estos temas en la tesis doctoral que vengo desarrollando en la PUC-RS: El Progreso en las Ideas. Escritos e Intelectuales positivistas en el Perú (1884-1919). Previsión de defensa: 2021.

${ }^{25}$ Con la excepción de los ensayos realizados por el Partido Republicano Riograndense a fines del siglo XIX, en el sur del Brasil, que también fueron objeto de interpretaciones divergentes (PINTO, 1986).
} 
De ese modo, el desarrollo teórico social de las tesis de Comte, mediado por la necesidad de recuperar el idealizado consenso perdido de su entorno, se resume en la llave por la que es conocida su filosofía. Para el autor francés, el orden se convierte en la "condición permanente del progreso, en tanto que el progreso es la constante finalidad del orden" (Cfr. GURVITCH, 1859: 59).

La teoría social elaborada por Spencer, se distingue de la Comte por ser individualista, decididamente biologista y derivar hacia diferentes consecuencias políticas. El inglés no solo entiende la sociedad como un organismo sino que afirma que la misma, así como toda realidad (cosmos), es un organismo vivo, por tanto, se encuentra regida por el mismo tipo de principios que determinan la vida de los seres biológicos. Como se refirió, el principio o ley universal será el de la evolución, todos las realidades (organismos) se encuentran sometidas a ella, puesto que se mueven indefectiblemente. De esa forma, los métodos de investigación de la ciencia biológica prestan un auxilio singular al desarrollo de la teoría social spencereana.

Spencer describe en sus Primeros principios dos tendencias holísticas que dirigen el proceso evolutivo universal, el tránsito del estado inconexo a otro más conexo y el del estado homogéneo o otro heterogéneo. Estas tendencias también antinómicas se reúnen de modo complementar en cada realidad en evolución, para el modelo spencereano, cualquier elemento deberá evidenciar las mismas. Una sociedad específica, por ejemplo, tiende a lo largo de su historia a integrarse, esto es, establecer mecanismos de comunicación e interrelación cada vez más ágiles y eficaces (conexión), pero al mismo tiempo los diferentes elementos que la integran adquieren mayor independencia en la medida en que se especializan en sus funciones, progresando infinitamente en su complejidad (heterogeneidad). El cuerpo, los conocimientos, las regiones climáticas, la moral, las razas y cualquier tipo de realidad existente estarán informados por estas tendencias, definidas como evolución, en las que encuentran su punto en común.

En sus escritos posteriores, Spencer expone un desarrollo de este principio a los diferentes ámbitos de la realidad social. La analogía absoluta entre los organismos vivos y las sociedades humanas implicará, para el autor inglés, el traslado de las condiciones favorables en que un determinado organismo evoluciona debidamente hacia el establecimiento de los principios que deben regir el desarrollo de las sociedades. Estas leyes naturales descritas por el proceso evolutivo se regulan, al igual que con los seres 
vivos, de modo espontáneo. De modo que la consecuencia necesaria es que cualquier tipo de intervención externa al proceso mediante el cual las sociedades evolucionan por propio impulso implicará un trastorno del ritmo evolutivo natural.

A diferencia de Comte, para Spencer la sociedad no necesita ser conducida a un estadio de mayor nivel de conocimiento, orden y por tanto progreso. Para el inglés este proceso se da, en razón de la dinámica de movimiento-evolución, de modo natural o espontáneo. De forma que lejos de precisar individuos introducidos en el modelo positivo o en un mayor nivel de evolución, la opción más adecuada para el desarrollo social será dejar hacer, esto es, colocar el mínimo de obstáculos posibles para el desarrollo individual. Consecuentemente, el mínimo de leyes necesarias para garantizar esa libertad de evolucionar "naturalmente", entendida por naturaleza no una sustancia o metafísica sino el orden espontaneo que describe la dinámica de evolución.

Los intérpretes de Spencer también han pretendido ver en la expansión imperial y el consecuente desarrollo del siglo XIX inglés, causas posibles de su indiferente optimismo fundado en la categoría de evolución (GAUPP, 1930; DURANT, s/f). La originalidad de sus tesis radica, entre otras razones, en el intento de sustentar el individualismo liberal en principios o supuestas leyes que definen naturalmente el curso de las sociedades, y el cosmos en general. La posibilidad de extraer estas leyes es dada, una vez más, por la aplicación del método de las ciencias (llave legitimadora).

Desde mi lectura, una diferencia sustancial de los presupuestos que informan las teorías de los "fundadores de la sociología" (RUMNEY, 1944: 45) es que para el inglés la noción de progreso no es absolutamente equivalente a consenso o armonía social. En tanto que para Comte estos son dos elementos necesarios y distintivos de todo verdadero desarrollo (el orden como presupuesto y finalidad del progreso), para Spencer el "auténtico" orden es el natural, es decir, aquel que se establece al librar al individuo y la sociedad de los diferentes tipos de intervenciones externas (estatales, corporativas). Este orden espontáneo, como lo demuestra la naturaleza, admite por veces tensiones, conflictos e "injusticias aparentes", todo ello como parte de una dinámica mayor de verdadero progreso o, en términos de Spencer, evolución.

El inglés entiende que armonía social implica, en todos los casos, desentendimientos y conflictos que son absorbidos por la dinámica de desarrollo, implicados en el consenso. En lo que supuestamente reflejaría la percepción de su 
propia sociedad que, a diferencia de la Francia posrevolucionaria, absorbería las inquietudes reformistas decimonónicas de modos más "pacíficos". No obstante, la consecuencia de la extensión de los principios que el mismo pretende inducir del proceso evolutivo hacia las regulaciones de la vida social, derivarán en posturas que lo aproximarían a las elaboraciones iniciales de lo que se conoce como darwinismo social (BANNISTER, 1979).

Las tesis de Spencer contradicen así todo exceso de intervención estatal o corporativa en la vida de los individuos, las relaciones que estos establecen entre sí estarían informadas por una lógica propia que es la idónea para su desarrollo. Esa lógica, dictada o descrita por el proceso de evolución, demuestra una dinámica intrínseca mediante la cual los organismos sociales regulan el desarrollo de sus funciones, que el inglés enuncia, utilizando la fraseología darwiniana, como la selección natural o lucha por la existencia. Así como el análisis científico del resto de las especies, que también forman parte de la evolución universal, evidencia el perfeccionamiento constante de sus funciones mediante la selección de los más aptos y la consecuente transmisión de la calidad de sus caracteres hereditarios a nuevas generaciones, los individuos y sociedades disputan entre sí las mejores condiciones de existencia, lo que de modo análogo contribuiría al progreso de la especie y sociedad humanas $^{26}$.

El filósofo inglés traslada así las explicaciones biológicas de su contemporáneo Charles Darwin (1809 - 1882), con cuyas tesis mantendría una compleja relación ${ }^{27}$, a la definición de las leyes que regulan el orden natural de las sociedades. Al igual que los individuos, los pueblos que han desarrollado un sistema de instituciones más elaborado y complejo están en mejores condiciones para sobrevivir que aquellos que viven en una sociedad primitiva. Ello, que es una constatación que desprende el análisis del proceso evolutivo humano, por tanto, lo que está dado, lo positivo o lo que se muestra a la

\footnotetext{
${ }^{26}$ Spencer se ocupa de describir estos procesos especialmente en sus principios de biología, sociología y moral, ya referidos (MONEREO, 2009).

${ }^{27}$ Las aplicaciones que Spencer realiza de la tesis de la selección natural de Darwin, expuesta en su Origen de las Especies (1859), fueron desautorizadas por este en su escrito posterior Origen del Hombre (1871). El debate sobre las relaciones entre la teoría evolucionista de Darwin y los desarrollos sociales de Spencer inicia en esos años y recibirá diferentes versiones (DI FILIPPO, 2003). En 1883, el científico británico Francis Galton (1822 - 1991), primo y antiguo alumno de Darwin, sustenta su teoría eugenésica en los desarrollos del darwinismo social (SOUTULLO, 1997). Como es sabido, los diferentes desarrollos teóricos del darwinismo social obtendrán una difusión amplia (y aplicaciones condenables) hacia las últimas décadas del siglo XIX y primera mitad del XX (PICK, 1993).
} 
observación, también será así lo bueno o moral. Para el filósofo británico, aquello que es demostrado a partir del análisis de la forma natural como las especies evolucionan tendrá que ser, en la lógica que el mismo sigue, lo más adecuado o favorable para las mismas, lo axiológicamente bueno. Así, el bien social será permitir que los grupos, sociedades y razas disputen entre sí, lo que espontáneamente derivará en la mejora de la especie humana y, si no en una armonía visible, aparente o inmediata, sí en la armonía evolutiva universal.

La teoría social de Spencer transita así desde la constatación del principio holístico de la evolución y el orden natural que se desprende del mismo, hacia una visión supuestamente optimista (indiferente) del devenir humano, que no dependiendo para su consecución de nada, además de reunir las condiciones de libertad necesarias para su desarrollo espontáneo, por tanto progreso auténtico, implicará la eliminación de cualquier intervención corporativa sobre la dinámica "armónica" de evolución, incluidos en ésta los conflictos que evidencian por veces injusticias aparentes. En tanto para Comte el orden social es origen y finalidad del progreso de la humanidad, para Spencer es el progreso, identificado con la evolución, el que define la naturaleza del verdadero orden universal.

Los desarrollos o versiones europeas del darwinismo social, que parten de las tesis spencereanas, serán objeto de diversas apropiaciones en los medios no europeos. Como se mencionó en la introducción, en los países latinoamericanos estas tesis desarrolladas por un amplio número de teóricos del organicismo sociológico o racismo científico serán objeto de diversos modos de apropiación (STABB, 1969; GLICK, 1999; MIRANDA y VALLEJO; 2005, CUVI, 2016). En el caso peruano, los intelectuales reconocidos como positivistas debatirán ampliamente las categorías que informaron este debate, no obstante, los usos de los que serán objeto las tesis spencereanas no se limitarán a sus derivaciones científico-racistas.

Un tema que concentró también la atención de los teóricos positivistas europeos fue el de la educación. Probablemente el texto más difundido de Spencer sea el tratado que sobre el tema publica en 1860 , Educación intelectual, moral y física ${ }^{28}$. Al igual que Comte, cree que esta deberá ser ministrada por etapas o progresivamente, siguiendo los niveles de evolución mental. No obstante, para el filósofo francés la labor educativa se

${ }^{28}$ Entre sus textos, el que recibió mayor número de traducciones (GAUPP, 1930: 250). 
inscribe dentro de las funciones del sacerdocio positivista, de modo que se garantice la difusión del modelo positivo de conocimiento (educación científica). El inglés, en cambio, incide en un régimen educativo que otorgue espacio al desarrollo espontáneo de quien se instruye que, con el mínimo de dirección, alcanzará las metas deseadas. Ambos coinciden en un punto, el contenido de la educación deberá estar despojado de cualquier tipo de apriorismo o modelo metafísico de conocimiento e informado por el método de las ciencias positivas.

Una vez más, se percibe la coincidencia de aproximaciones en la crítica a un modelo de conocimiento que primó en los saberes tradicionales, a partir de cuyas interpretaciones los individuos organizaron por más de un milenio sus diversas formas de vida social, y la también coincidencia en la novedad de la aplicación del método de las ciencias, lo que sería el rasgo más característico del positivismo: la fe en la unidad del método científico. Será precisamente este nuevo "fuego de los dioses" el que reunirá a estos disímiles prometeos, de la segunda mitad del siglo XIX, en una "escuela" o categoría común que se conviene en enunciar como positivismo. Aun elaboraciones tan diversas en sus formas o contenidos como las de Comte y Spencer, tendrán en común su herramienta teórica y métodos así como las preocupaciones o fines que persiguieron por caminos diferentes. La especial atención dada por intelectuales y estadistas del período a estos dos autores se debió a los desarrollos que sus sistemas o conjunto de textos alcanzaron, así como a la novedad de sus diferentes aplicaciones del método positivo. Coincido así con la afirmación de Fréderic Harrison, quien en el año 1885 (las Razones de Spencer aparecen en el 64) afirma:

"Hasta donde sé, después de Hegel solo se han producido dos sistemas que hayan abarcado el conjunto de conocimientos humanos: el de Comte y el de Spencer. Estos dos sistemas difieren esencialmente de todos los demás sistemas de filosofía que les precedieron. Pero los dos son prácticamente iguales en el fin, el método y la base. El fin que persiguen es amalgamar la ciencia, la filosofía, la religión, y formar un cuerpo de doctrina coherente que abarque en su totalidad las cosas del pensamiento y de la vida. Su método consiste en transformar la ciencia en filosofía y, por consiguiente, en hacer que todas las ciencias particulares-ciencia física, ciencia social, ciencia moralsufran el yugo de una lógica enorme" (Cfr. KREMER-MARIETTI, 1997: 97).

\section{Positivismos locales}


Por lo expuesto antes, considero adecuada una aproximación al estudio de lo que, en razón de su diversidad, prefiero denominar las tesis positivistas, que centre su foco de análisis en las aplicaciones o usos del método positivo. Teniendo algunos cuidados necesarios. En primer lugar, distinguir entre la diversidad de las tendencias o aplicaciones que se reúnen en este conjunto. Como se dijo, es problemática la utilización del término positivismo pues, desde el punto de vista del método, éste reúne desarrollos que se distinguen entre sí, pero que a su vez tienen un elemento en común que viabiliza o impele el análisis conjunto. De forma que, al referir estas categorías en los textos de un autor local, deberá establecerse de que tendencia o combinación de tesis positivistas se está hablando. Es válido, en ese sentido, referir un positivismo comteano, un positivismo "heterodoxo", un positivismo evolucionista y, a su vez, distinguir entre las diferentes versiones comprendidas en estos enunciados, siempre provisionales.

Por otro lado, atender en la lectura de las fuentes las perspectivas o puntos de vista de los intelectuales en estudio sobre los marcos de la denominación en cuestión que también admitió diferentes posiciones, no siempre coincidentes con la que se elige para el análisis. En tanto para los “científicos” mexicanos, por ejemplo, positivismo refiere cualquier desarrollo del método científico, para los “ortodoxos" brasileños el término se agota necesariamente en la observación del conjunto de la obra comteana. El debate intelectual peruano de entre siglos también deja trasparecer estas ambigüedades del lenguaje filosófico $\mathrm{y}$, por consecuencia, político. Es decir, atender a las imprecisiones que la polifonía del término contribuyó a generar en la comunicación o debate intelectual local.

Finalmente, tener presente que la adopción de una perspectiva de análisis, en cuanto a los contenidos del positivismo, parte siempre de una toma de posición, esto es, inscribirse dentro de una de las convenciones conceptuales por considerarla la más adecuada o fructífera para el estudio. Como demuestran los debates que sobre la categoría realizaron los intelectuales decimonónicos, determinar los marcos o contenidos teóricos precisos del "positivismo" parte de diferentes perspectivas, todas ellas defendibles desde un punto de vista. De forma que, no existiendo una verdad sobre el punto, nos encontramos ante convenciones conceptuales. Mi opción por centrar el análisis en lo que se enuncia como "método" parte de la constatación de que, en una mayoría de los casos, los intelectuales latinoamericanos efectuarían un uso o 
apropiación de las tesis positivistas que atendería a la supuesta cualidad del método positivo, a semejanza de sus pares europeos. Para una ostensible mayoría de los intelectuales que podemos denominar positivistas, en razón de las re-elaboraciones diversas que harían de estas categorías, el atractivo del positivismo consistiría específicamente en su nueva "fe". De forma que restringir la extensión de la categoría a los marcos de los desarrollos comteanos limitaría, a su vez, la percepción adecuada de la amplitud o forma como el fenómeno o proceso estudiado operó.

\section{Referencias bibliográficas}

ALJOVIN, Cristóbal (2000). Caudillos y constituciones. Perú: 1821 - 1845. Lima: IRAFCE.

ANDERLE, Adam. (1988). El positivismo y la modernización de la identidad nacional en América latina. Anuario de Estudios Latinoamericanos, XLV, UNAM (México).

ARANA, Hermas Gonçalves (2007). Positivismo: reabrindo o debate. Campinas: Autores Associados.

ARDAO, Arturo (1950). Espiritualismo y Positivismo en el Uruguay. Filosofías universitarias de la segunda mitad del siglo XIX. Buenos Aires: FCE-Tierra Firme.

BANNISTER, Robert C (1979). Social darwinism: science and myth in AngloAmerican social thought. Philadelphia: Temple.

BENOIT, Lelita (1999). Sociologia comteana. Gênese e devir. São Paulo: Discurso editorial.

BILBAO, Andrés (1986). El positivismo y la sociología. Madrid: Editorial Saltes.

CAPONI, Gustavo (2001). Claude Bernard y los límites de la fisiología experimental. História, Ciências, Saúde - Manguinhos, vol. VIII(2): 375-406, jul.-ago.

CARDOSO JR., Hélio R. (2001). Tramas de Clio. Convivência entre filosofia e história. Curitiba: Aos Quatro Ventos.

CHARLTON, D.G. (1959). Positivist thought in France during the Second Empire: 1852-1870. Oxford: Clarendon Press.

CHEVRILLON, Andre (1932). Taine. Formation de sa pensée. Paris: Librairie Plon.

COBO, Rosa (1994). Como leer a John Stuart Mill. Madrid, Jucar.

CUVI, Nicolas Edit. (2016). Evolucionismo en América y Europa. Madrid: Doce Calles-FLACSO-UNAM.

DE LA VEGA, Marta (1997). Evolucionismo versus positivismo. Estudio teórico sobre el positivismo y su significación en América Latina. Caracas: Monte Avila Editores.

DEVOTO, Fernando (1992) Entre Taine y Braudel. Itinerarios de la Historiografía Contemporánea. Buenos Aires: Biblos.

DI FILIPPO, Josefina (2003). La sociedad como representación. Paradigmas intelectuales del siglo XIX. Buenos Aires: Siglo XXI-UB.

DURANT, Will (S/f). A filosofia de Herbert Spencer. Rio de Janeiro: Ediouro. 
FORTE, Miguel (1998). Sociología, sociedad y política en Augusto Comte. Buenos Aires: Eudeba.

FOUILLÉE, Alfred (1896). Le mouvement positiviste et la conception sociologuique du monde. Paris: Ancienne Librairie Germer Bailliére.

GAUPP, Otto (1930). Spencer. Madrid: Revista de Occidente.

GLICK, Thomas F. (edit) (1999). El darwinismo en España e Iberoamérica. México: UNAM.

GOBERNA FALQUE, Juan (2012). La Amarga Epopeya . Una biografía intelectual de Augusto Comte. Estudio Preliminar. En: COMTE, Augusto. Física Social. Madrid: Ediciones Akal.

GRUBER S.J. (1893) Le Positivisme depuis Comte jusqu'a nos jours. París: P. Lethielleux Libraire-Éditeur.

GUADARRAMA, Pablo (2004). Positivismo y antipositivismo en América Latina. La Habana: Editorial de ciencias sociales.

GUERRA, Fraçois-Xavier (1995). Del Antiguo Régimen a la Revolución. México: FCE, 2 tomos.

GURVITCH, Georges (1955). Tres capítulos de historia de la sociología: Comte, Marx y Spencer. Buenos Aires: Galatea-Nueva Visión.

GUTHLIN, L'abbé (1873). Les doctrines positivistes en france. Paris: Bray et Retaux.

HALE, Charles (1991). Ideas políticas y sociales en América Latina, 1870-1930. En: BETHELL, Leslie (Org.). Historia de América Latina. Barcelona: Editorial Crítica, tomo 5.

HUBERT, René (1943). La doctrina de Augusto Comte. Introducción a Comte: selección de textos. Buenos Aires: Sudamericana.

JARAMILLO, Jaime (1964). El pensamiento colombiano en el siglo XIX. Bogotá: Edit. Temis.

JUNIOR, Jõao R. (2003). Augusto Comte e o positivismo. Campinas: Edicamp.

KOLAKOWSKI, Leszek (1988). La filosofía positivista. Ciencia y filosofía. Madrid: Ediciones Cátedra.

KREMER-MARIETTI, Angèle (1997). El positivismo, México: Publicaciones Cruz.

LACERDA, Arthur V. (2000). A república positivista. Teoría e ação no pensamento político de Augusto Comte. Curitiba: Juruá.

MARTÍ, Oriol (2006). Claude Bernard y la medicina experimental. España: Ediciones de Intervención Cultural.

MIRANDA, Marisa y VALLEJO, Gustavo (2005). Darwinismo Social y Eugenesia en el Mundo Latino. Buenos Aires: Siglo XXI.

MAGNINO, Bianca (1955). Storia del Positivismo. Roma: SES.

MONEREO PÉREZ, José Luis (2009). La ideología del darwinismo social y la filosofía social de Spencer. Estudio Preliminar. En: SPENCER, Herbert. Los primeros principios, Granada: Editorial Comares.

NEGRI, Antimo (1981). Positivismo Europeo. Firenze: Le Monnier.

NEVES, Lúcia B. (2003). Corcundas e constitucionais. A cultura política da independência (1820 - 1822). Rio de Janeiro: Revan-Faperj.

OLMSTAD, J.M. (1951). Claudio Bernard. Fisiólogo. Buenos Aires: Edic. Peuser.

OUELBANI, Mélika (2010). Qu'est-ce que le Positivisme. Paris: Librairie Philosophique J. Vrin.

PALTI, Elías (2005). La invención de una legitimidad. México: FCE.

PETIT, Annie (1978). D'Auguste Comte à Claude Bernard, un positiviste déplacé. In: Romantisme, 1978, $\mathrm{N}^{\circ}$ 21-22. Les positivismes, pp. 45-62. 
PICK, Daniel (1993). Faces of Degeneration: A European Disorder, c. 1848-1918. Cambridge: Cambridge University Press.

PINTO, Celi J. (1986). Positivismo. Um projeto político alternativo (RS: 1889-1930). Porto Alegre: LPM.

POGGI, Stefano (1987). Introduzione a il Positivismo. Roma-Bari: Editori Laterza.

PRIETO, Justo (1944). La vida indómita de Augusto Comte. Un apostol de una religión sin dios. Buenos Aires: Editorial Ayacucho.

QUINTANILLA, Pablo (2006). La recepción del positivismo en Latinoamérica. En: Logos Latinoamericano 2a época, Año I, $N^{\circ}$ 6, Lima, pp. 65-76.

REIS, José C. (2004). A História, entre a filosofia e a ciência. Belo Horizonte: Auténtica.

RUMNEY, Judah (1944). Spencer. México: FCE.

SALAZAR, Augusto (1967). Historia de las ideas en el Perú contemporáneo. Lima: Moncloa Editores, 2 tomos.

SALDARRIAGA, Oscar (2006). Los métodos positivistas en Colombia. Siglo XIX. Mimeo.

SIMON, Walter (1963). European positivism in the nineteenth century: An essay in intellectual history. New York: Cornell University Press.

SOUTULLO, Daniel (1997). La eugenesia. Desde Galton hasta hoy. Madrid: Talasa.

STABB, Martin S. (1969). América Latina en busca de una identidad: modelos del ensayo ideológico hispanoamericano, 1890-1960. Caracas: Monte Avila.

TERAN, Oscar (1983). América Latina: Positivismo y Nación. México: Editorial Katún.

THOMPSON, Kenneth (1983). Augusto Comte. Los fundamentos de la Sociología. México: FCE.

TRINDADE, Helgio (Org.) (2007). O Positivismo. Teoría e Prática. Porto Alegre: UFRGS.

VALVERDE, Carlos (2003). Génesis, estructura y crisis de la modernidad. Madrid: BAC.

VIRTANEM, Reino (1960). Claude Bernard and his place in the History of Ideas, Lincoln: Univ. of Nebraska.

WOODWARD, Ralph L. (1971). Positivism in Latin America, 1850 - 1900. Lexington: Heath and Company.

ZEA, Leopoldo (1976). El pensamiento latinoamericano. Barcelona: Editorial Ariel.

Artigo recebido em 18 de abril de 2019.

Aprovado em 04 de dezembro de 2019.

DOI:10.12957/intellectus.2019.42056 